\title{
"Esbozos, de capítulos posibles, a lo sumo»': traición y reescritura en dos novelas argentinas con colofón de un escritor húngaro
}

Palabras clave: literatura argentina, trauma, Guerra Sucia, ruptura, traición

\section{Ruptura, traición y trauma en la literatura}

En el siglo XXI, y ya a finales del siglo XX la literatura hace mucho que no sueña con grandes historias, grandes verdades, grandes revelaciones, perspectivas únicas y fiables. Al mismo tiempo, parece que nuestro presente (en un sentido amplio) todavía tiene mucha deuda -con circunstancias, hechos y tragedias de los últimos cien años- que da lugar a una categoría en la literatura que podemos caracterizar con expresiones como ruptura (en varios sentidos), trauma, y traición. «[...] Desde sus orígenes nuestras ficciones están atravesadas por la traición», dice Lilana Heker en su ensayo titulado Las formas de la traición en la literatura argentina (2009). Parece que, de la traición, y el trauma que esta significa, surge una necesidad de reescribir el pasado que los precede para que de alguna manera se intente reconstruir la continuidad del tiempo y encontrar la posibilidad de la integración de las identidades afectadas.

Lo que proponemos en este artículo es un acercamiento interdisciplinario (partiremos de una investigación psicoanalítica), e intercultural (citaremos el caso de un escritor húngaro) para comparar dos novelas argentinas, una de Liliana Heker, El fin de la bistoria, y la otra, titulada Una misma noche, ganador del premio Alfaguara en 2012, escrita por Leopoldo Brizuela. El tema no sería tanto el surgimiento de la tradición de la traición (que parece ser, junto al

$1 \quad$ La cita del título es de una de las novelas analizadas en el artículo: Leopoldo Brizuela, Una misma noche. (Véase referencia en la bibliografía.) 
trauma que causa, una de las experiencias fundamentales y uno de los principales temas literarios del siglo XX, tanto en Argentina como en muchos otros países), sino las consecuencias, y las posibles formas de textualizar el proceso psicológico de asimilar o elaborar los hechos que en los dos casos tienen que ver con la Guerra Sucia en Argentina. En las dos novelas los autores optan por técnicas narrativas que incluyen la fragmentariedad y la polifonía como reflejo del funcionamiento de la memoria humana, y la reescritura explícita que implica la presencia textual del autor-narrador-personaje quien, al mismo tiempo de contar una o varias historias, ofrece también una mirada metaficcional sobre su propio texto.

La consecuencia de estos hechos es una literatura de búsqueda de formas de expresión que permiten reflejar el proceso de enfrentarse con un pasado traumatizante, tanto desde el punto de vista de los supervivientes en un sentido estricto, como desde la perspectiva de los que se veían afectados por las circunstancias y las condiciones de estos sistemas políticos y locuras terroríficas.

Imre Kertész, el premio Nobel húngaro, conocido sobre todo por su novela Sin destino en el que cuenta su experiencia en Auschwitz, en su último libro, La última posada nos ofrece un paso más en el intento de la textualización del trauma, y dice lo siguiente:

Pero que si el novelista omnisciente como tal ya no existe. Y si a pesar de esto nos manejamos en tercera persona y no podemos evitar la omnisciencia... Quizá haya logrado crear si no la solución, pero de todas formas una posible solución: [...] la realidad de la obra de ficción es otra obra de ficción. Además, esta otra obra no la conocemos en su totalidad. Es tan confusa, como la Creación misma, o como lo es la realidad que nos ha tocado a nosotros. Y tan fragmentada también, aunque en cierta medida perceptible, ya que al fin y al cabo vivimos según la lógica que nos brinda (Kertész, 2016: 25).

Este fragmento nos puede servir como una especie de guía para interpretar las dos novelas argentinas en cuestión, puesto que en ambos casos se trata justamente de esto: resulta que la realidad de la obra de ficción es otra obra de ficción.

Si consideramos la fusión de las realidades de los autores con las ficciones creadas por ellos (fenómeno que conocemos desde Cervantes) así como la presencia explícita de distintas versiones de los hechos (visión la cual es muy 
típica en Borges, para mencionar la otra figura que da título a la presente publicación) para dejar una huella textual de los cambios mentales y presentarlo todo como un proceso, surge la cuestión de cuál es el próximo paso de dicho desarrollo en el texto mismo, si no queremos quedarnos con «la página en blanco» que menciona Umberto Eco como obstáculo principal de la reflexión textual de una realidad destruida (Eco, 1985). Aquí tenemos que mencionar que el trauma sí puede causar silencio, es más, Anna Menyhért, especialista húngara de teorías del trauma describe de la siguiente manera las características de la lengua traumatizada: «lo propio del trauma es que invita, obliga a callar (tanto si el trauma es individual como si afecta a toda una sociedad)» (Menyhért, 2008: 25). De aquí que a los textos de trauma no hay que acercarse desde las narraciones tradicionales, sino desde el silencio. Cabe mencionar en este punto que Brizuela en su libro sí llega si no a la página en blanco, pero sí a la página en negro, que Emilia Deffis en su artículo sobre la novela interpreta como la «oscuridad de la memoria» y al mismo tiempo «la claridad de la escritura» (Deffis, 2016: 15), puesto que en la estructura del libro cada capítulo recibe una letra del alfabeto, y a la página en negro corresponde la última letra, la zeta.

La misma Anna Menyhért dice también que «para superar el trauma hace falta narrarlo, contarlo, y que la dificultad está en que la memoria traumatizada se distingue del funcionamiento normal de la memoria» que, aunque siempre engaña, tiende a construir historias y a encontrar una lógica de causa-efecto entre los hechos. En el caso de las dos historias en cuestión esta es la lógica que falla y este es el fallo que deja huellas en los textos como la fragmentariedad, la repetición, la vuelta una y otra vez al mismo hecho o a la misma obsesión que en las historias en cuestión es escribir una novela.

\section{Las dos novelas argentinas: El fin de la historia (1996) de Liliana Heker y Una misma noche (2012) de Leopoldo Brizuela}

Vamos a presentar brevemente cómo se construyen las dos novelas argentinas, para ver después los puntos de vista y las observaciones psicoanalíticos en relación a la lengua, así como las soluciones de los dos autores para reflejar la problemática en cuestión. En el libro de Liliana Heker se cuentan los esfuerzos de una mujer, Diana Glass, para escribir un libro en la que quiere explicar la historia de su amiga, Leonora Ordaz, militante revolucionaria de los Montoneros que acaba capturada y torturada por los militares. 
Diana y Leonora son amigas desde la infancia, Diana quiere ser escritora y escribir la historia de Leonora, cuando ésta desaparece. Leonora y su marido, Fernando, luchan contra la dictadura militar, tienen una hija de 10 años. Un día se llevan a Leonora y la torturan hasta que descubren su inteligencia y su disposición para colaborar. Poco a poco se la ganan, escribe un informe detallado sobre los militantes y al final llega a tener una relación sentimental con el que había sido su torturador. Por tratar el tema de una traición de este tipo la novela despertó mucha polémica, ya que ciertos sectores la consideraron justamente como una traición a la memoria de las víctimas del terrorismo de Estado, como explica también Carlos Hernán Sosa en su artículo sobre la lectura de la dictadura de Lilana Heker (Sosa, 2008). Diana está obsesionada con escribir la historia de su amiga heroica, pero no es capaz de hacerlo, quizás porque no sabe cómo termina, cuál es el fin de la bistoria. En un café conoce a una escritora que le invita a su taller de escritura donde se encuentra con Garita, un escritor homosexual que no le cae nada bien. En la última sesión, después de haberse enterado del final de la historia de Leonora (se encuentran en la calle), le cuentan que Garita también fue capturado por los militares: resulta que el que menos parecía pintar era el que tenía una verdadera historia y la de Leonora no es la que Diana pensaba. Leonora, como dice Diana, «bebió hasta el fondo la copa de la vida», pero eso «no siempre es una virtud», concluye el final de la novela que tenemos en la mano y que trata del proceso fracasado de la escritura de esta otra novela.

El argumento de la obra de Leopoldo Brizuela, de manera muy simplificada, es el siguiente: Leo es escritor, escribe dos historias paralelas, una del 1976, y otra de 2010. Los dos hechos ocurren en el mismo lugar, en la misma cuadra, en la misma casa donde «entran». A propósito de lo que ocurre en 2010 (presente) empieza a recordar e intenta reconstruir lo que había pasado en 1976 cuando él era un niño y vio cómo su padre acompañaba a unos militares al jardín de la casa vecina para que pudieran entrar por una puerta secreta. Durante la historia va descubriendo los detalles del asunto de una empresa de papel que tiene que ver con los otros vecinos (el caso Papel Prensa), pero la escena de su padre pateando la puerta vecina no puede quitársela de la cabeza y los recuerdos siempre cambian hasta que ya no le queda más que la lógica de un sueño y el papel en negro. El texto se compone de cuatro grandes unidades: 1. novela, 2. memoria, 3. historia, 4. sueño. Cada una de ellas tiene su propia lógica y contiene una variante de los recuerdos del narrador de la noche de la traición de su padre. El recuerdo es borroso, incontrolable y sin una versión señalada como verdadera. La última aparición del padre representa perfectamente esta 
metamorfosis, que al mismo tiempo son las últimas líneas de la novela dentro de la novela:

La primera patada me da en el pecho y ahogo el grito: "Papá", y de inmediato entiendo qué significa papá en el lenguaje de ellos: "el que abre la puerta".

Todos ríen y lo incitan a más.

Vuelve a patearme el estómago. Y entonces sí, claro, entonces sí. [...]

Caigo, caigo, caigo, mirando allá arriba la casa que se aleja en la ira del cielo hasta volverse un punto.

Hasta que topo el agua con la espalda dolida y en mi vientre un cadáver y las víboras de la locura que flotan en el agua empiezan a morderme los tobillos, los brazos, la cabeza.

Pero yo no digo nada. Callo.

Y sobre mí se cierra el mar del olvido (Brizuela, 2012: 261).

Vemos que se trata de dos historias que tienen en común el período políticohistórico de la Guerra Sucia en Argentina, así como el deseo e intento de escribir una historia dentro de otra historia que se consigue en distintas medidas: en los dos casos el lector recibe una novela, una narración completa, pero ninguno de los dos narradores se siente satisfecho con lo que logra escribir. En la cita final del texto de Brizuela vimos el «fracaso» de Leo, la otra narradora, Diana, lo reconoce explícitamente en el último capítulo (después de haber vuelto a ver a su amiga): «Lo primero que descubrí es que ya nunca voy a poder escribir esa novela» (Heker 1996: 223).

\section{La lengua traumatizada en las dos novelas}

En ambos textos nos encontramos con un intento fracasado de contar una historia, es decir, ocurre algo parecido que en el caso de pacientes psiquiátricos que mucho después de vivir un trauma quieren hablar de lo que les había pasado, pero no lo logran, o no del todo, porque resulta que la experiencia que habían tenido afecta la capacidad lingüística.

Juliet Michell, psicoanalista británica en su artículo titulado Trauma, Recognition, and the Place of Language escribe de casos concretos de pacientes que habían sufrido un trauma, pero que pensaban haberlo superado hasta que a 
la hora de empezar a hablar de ciertos problemas que tenían (y que en su acepción no tenían nada que ver con el acontecimiento traumático) se dieron cuenta de que no eran capaces de reconstruir los hechos del pasado, o, de todas formas no eran capaces de narrarlos de manera coherente. En los dos casos tratados la respuesta que han dado los pacientes al acontecimiento traumático implicaba un cambio que tenía que ver con la lengua: desde la afonía o afasia (que correspondería al silencio), hasta cambios más difícilmente descriptibles, pero que tenían algunas características en común que la psicoanalista describe de la siguiente manera:

Como consecuencia inmediata de un trauma frecuentemente aparece una inseguridad respecto al habla, o esto también puede afectar la capacidad de la correcta pronunciación de las palabras. Este fenómeno tiene su explicación fisiológica. Sin embargo, lo que yo quiero señalar es que existen también paralelismos psicológicos. Mis pacientes que a mi modo de ver padecen de una forma respectiva de un trauma, tienen una relación especial con la lengua. El trauma causa un daño que hace que la personalidad se vacíe y esto puede dejar enojo u odio. Sin embargo, es un estado poco sostenible, por lo tanto, muchas veces da lugar a un pseudoestado o a un estado fingido (Michell, 1998: 129).

En el caso de nuestros textos el vacío se manifiesta justamente en la búsqueda de la forma de narrar las experiencias respectivas y los dos narradores están conscientes de las dificultades, en ambos textos encontramos reflexiones sobre el proceso de escribir y sobre la problemática de la posibilidad-imposibilidad de la escritura a la hora de no saber exactamente qué es lo que se esconde detrás de los juegos de la memoria o la fantasía. La protagonista-escritora de El fin de la bistoria procura rellenar los huecos con su fantasía, mientras que el narrador de Una misma noche se esfuerza cada vez más para llegar a saber cuál es la versión correcta de los recuerdos que tanto cambian. Ni siquiera se atreve a hablar de la novela que está escribiendo porque está consciente del riesgo. Por eso, cuando le preguntan por su futuro libro, dice lo siguiente: «Ah, no es una novela - minimicé, avergonzado: temía tener que admitir, más tarde, otro fracaso. - Solo escribí apuntes» (Brizuela, 2012: 81).

Diana, en El fin de la bistoria, refiriéndose a sí misma en tercera persona, escribe explícitamente de los cambios que sufre constantemente la historia que no llega a escribir: 
La historia continuamente se le modifica, se le vuelve esperanzada, o aventurera, o trágica, por eso ahora mismo [...] conmovida por un impulso arrasador pero carente de derrotero, añora, entre otras cosas que añora, ese estado de gracia o de fe de la tarde en el café Tiziano, cuando por ¿segunda? vez se le ocurrió contar una historia. Que todavía no era del todo la que fue armando después. Y mucho menos ésta (Heker, 1996: 35).

La modificación continua se hace incluso visible, la superposición de voces o el diálogo de textos sirven como una especie de manifestación de los esfuerzos textuales para escribir una historia. Los dos autores usan la misma técnica tipográfica, la cursiva, para visualizar las distintas voces como veremos a continuación. En la cita de El fin de la bistoria incluso aparece una tercera voz, en estilo directo, señalado con comillas:

Hay que amar la vida, anotará Diana días después, mientras la Bechofen la observará desde otra mesa y pensará: «Demasiada pasión para darle alguna forma a eso que está escribiendo. Y sin embargo no está ahí el germen de toda obra, en la pasión?», bay que venerar la vida para tan siquiera sospechar cuánto de sagrado encierra una mujer que camina por la calle (Heker, 1996: 30).

En la otra novela encontramos la misma superposición de voces que resaltan el carácter borroso de los recuerdos que, además, como ya lo hemos dicho, se repiten siempre con alguna modificación. En el siguiente ejemplo podemos ver una de las tantas versiones de la escena más repetida del texto:

Cuando vuelvo a entrar en casa, mi madre aún está en la vereda: el tipo la ha dejado sola, pero ella no se anima a volver adentro, a escabullirse dentro, a ver dónde me metí, en dónde está mi padre, qué pasa con nosotros. Pero temo que lo haga, y me siento al piano. ¿Cómo podría decirle lo que vi? ¡Si al menos estuviera, ella también, enajenada!

La cara de mi padre cuando patea la puerta. ¿Por qué ni piensa en nosotros?

Me siento en el taburete y me pongo a tocar.

Que nadie más la baya visto es mi único consuelo (Brizuela, 2012: 123-124). 
Esta superposición de voces puede ser entendida como una presencia paralela de distintos momentos: las dos narraciones tienen su presente (después de la dictadura) que se separa claramente del momento recordado -Brizuela hasta construye el texto como una dialéctica de los dos momentos y pone al principio de cada parte en qué año estamos en la narración- para que el hecho de recordar esté explícitamente marcado.

El resultado de la doble narración y del diálogo entre el texto marco (el que cuenta el fracaso) y el texto interior (el texto fracasado) es, pues, una construcción en la que las distintas voces forman dos niveles en la narración. Volviendo a la investigación de la psicóloga, Juliet Michell afirma también que «El que sufre un trauma, se retira de la realidad y queda en su propio nivel lingüístico, pero después la lengua se ve cargada de una nueva energía y de esta manera se forman dos niveles lingüísticos. La lengua hablada es la de un consenso fingido o una repetición obsesionada» (Michell, 1998: 129). Podemos observar este último en los dos textos literarios: en ambos casos hay ciertas repeticiones presentes durante toda la historia, para citar un ejemplo de la novela de Heker, hay ciertas frases que reaparecen en distintos momentos de la narración, en distintos contextos, como la ya citada «beber hasta el fondo la copa de la vida». Vemos el mismo fenómeno en otro nivel y de manera más llamativa en Una misma noche también donde justamente esta «misma noche» que aparece en el fragmento arriba citado es la que se repite tantas veces (el intento y el fracaso de contarla), siempre en una versión diferente, como lo señala ya el título.

Otra conclusión de la psicoanalista es que «La lengua del trauma es una versión verbalizada de la lengua visual de los sueños», dice que «las palabras son metáforas, símiles, símbolos, disponen del estatus interior pero no interiorizado de los objetos y expresan más bien emociones y no significados» (Michell, 1998: 132), con lo que podríamos describir perfectamente la última versión o intento (del capítulo titulado justamente Sueño) de narrar los hechos así como los ecos que estos habían dejado en el narrador-autor de Leopoldo Brizuela.

Hay otro aspecto en común en los dos textos que tiene que ver con el sueño, aunque de una manera más abstracta y es que no solo es borroso el límite entre realidad y recuerdos, sino también lo es el límite entre ficción y autorreferencialidad. No necesariamente tiene por qué ser criterio de análisis, pero las interpretaciones de El fin de la bistoria casi siempre identifican a Diana, la narradora, con Liliana Heker, la autora, por la aproximada coincidencia de fechas, por el hecho de ser escritoras y tocar también el tema del papel de un escritor en una época de dictadura. En el caso de Una misma noche las condiciones del 
narrador-escritor hablan por sí: Leopoldo Brizuela crea un personaje que se llama Leo Bazán, escritor homosexual como él, que tiene la misma edad, la misma formación, etc. En una entrevista el autor, contestando a la pregunta sobre qué tiene el protagonista de él, dice:

Tiene en principio la misma motivación, y un nombre muy parecido para interpelar aún más la cercanía del lector. [...] Tenía que buscar un personaje de mi generación, con esas vivencias, alguien que entró en la secundaria el mismo día del golpe, que siguiera esos mismos pasos hasta la universidad y después. Un personaje que enfocase esa maldad que se vivía en aquellos momentos (Garrido, 2012).

No solo la implicación de la realidad del autor tiene su objetivo, sino también la obsesión de los personajes-escritores-narradores, que explican ellos mismos. Diana, en El fin de la bistoria, hablando con su mentora, resume su motivación y empeño de escribir así:

Se trata de lo que quería contar. La historia de una mujer persiguiendo hasta el final nuestro sueño de un mundo del que no tuviéramos que avergonzarnos. Era, no sé, era el homenaje a una generación, a los muertos de una generación que alcanzó a escuchar la campana del colegio y creyó tocar el socialismo con las manos. Y a los sobrevivientes de esa generación también, por qué no. [...]Por eso necesitaba una heroína, para fijar su historia como un cristal. O como un credo, a pesar de todo (Heker, 1996: 223-224).

Leo, en Una misma noche, también tiene claro por qué vale la pena, a pesar de las dificultades, la resistencia e incluso el riesgo de la imposibilidad de llegar a saber la verdad: «Y comprendo que la escritura es una manera única de iluminar la conexión entre el pasado y el presente. $Y$ eso me alienta a empezar: no como quien informa, sino como quien descubre» (Brizuela, 2012: 43).

\section{Conclusiones y colofón de Imre Kertész en La última posada}

Respecto a la cuestión de por qué forzar la narración de los hechos si hay tanta resistencia, el protagonista de Leopoldo Brizuela y la ya citada investigadora, Anna Menyhért, dan una respuesta muy parecida, aunque ella va un poco más allá en la explicación y considera la escritura un método terapéutico: «Porque hace falta la narración, puesto que el proceso de curación está en la lengua, en 
este lenguaje que no cubre sino descubre el trauma y eleva la ruptura hasta la superficie, la ruptura tiene que hacerse ver porque solo así es posible la nueva conexión entre pasado y presente» (Menyhért, 2008: 5).

La lengua, por lo tanto, que sirve para escribir este tipo de experiencias, «no puede ser ingenua, tiene que contener las dudas, la desconfianza, la angustia, la ruptura: la literatura del trauma no solo se distingue en sus temas, sino también en su lenguaje que al mismo tiempo se nutre del lenguaje de la experiencia de las rupturas de la primera mitad del s. XX en el que ya está presente el aspecto incontrolable de la lengua, el cuestionamiento de los valores, papeles y reglas tradicionales» (Menyhért, 2008: 9).

Hemos mencionado al comienzo que el fenómeno de escribir sobre este tipo de experiencias traumáticas en forma de novela aparece de una manera muy llamativa en el último libro de Imre Kertész que se titula La última posada. El caso del autor húngaro nos sirve como colofón (en el sentido de «remate, final de un proceso») porque él escribe la historia de una novela que finalmente no logra escribir, mientras que en las novelas argentinas el texto dentro del texto no se concluye, pero el lector sí tiene en la mano una novela que puede percibir como tal, o sea, una novela sobre el fracaso de escribir una novela. Lo que hace Kertész es una última protesta contra aquellas fuerzas que le han quitado el destino no solo a él, sino a muchas otras personas en cuya vida en un momento dado «irrumpió la Historia», con palabras de Liliana Heker en El fin de la bistoria. Si observamos la estructura que se refleja en el índice del libro del escritor húngaro, vemos cuántas páginas ocupan las simples «notas» y cuántas los verdaderos «intentos». De la proporción de ambos ya podemos sospechar el fracaso: I. Secretos abiertos (notas), 7-156 (149 páginas), II. La última posada (primer intento), 157-198 (41 páginas), III. El jardín de las trivialidades (notas), 199-372 (173 páginas), IV. La última posada (segundo intento), 373393 (20 páginas). El texto es mucho más una serie de reflexiones que cualquier tipo de narración, de vez en cuando aparece algo parecido a una historia que podría llegar a formar un texto coherente, pero la novela no deja de ser un «intento» (o dos) como señala él mismo en el índice. Sin embargo, el deseo de escribir la novela, como leit motiv está ahí continuamente (y, además, une esta novela con los dos textos argentinos), como vemos en los siguientes ejemplos:

La novela como un hijo tardío, mimado y frágil, despierta muchas preocupaciones en su viejo padre. [...] No me extrañaría encontrarla muerta un día (Kertész, 2016:16). 
Decidir si hace falta escribir esa novela. [...] ¿No será que quiero contar una historia que no es posible o que yo no pueda contar? (Kertész, 2016: 17)

La novela no está en ninguna parte (Kertész, 2016: 71).

La novela está agonizando bajo los golpes de mi impotencia. Apenas queda esperanza para salvarla (Kertész, 2016: 76).

No sólo hace falta investigar la existencia con los métodos de una novela, sino ver también lo inútil que es la búsqueda de los problemas de la existencia hoy en día, y por lo tanto lo inútil que es la novela, y el novelista lo es aún más» (Kertész, 2016: 12).

Realmente la agonía minuciosamente detallada del cuerpo (de su cuerpo), se convierte en una agonía del texto, de la novela. En su caso la Guerra Sucia es Auschwitz, el holocausto es la experiencia de la que de alguna manera u otra escribe en todos sus libros (otra vez la constante repetición como huella lingüística del estado postrauma). Lo que concluye sobre Auschwitz y su importancia, vale perfectamente para la Guerra Sucia y otros hechos traumáticos del siglo XX o cualquier otro momento de la historia:

Auschwitz pasó, y el hecho de que hubiera pasado (que hubiera podido pasar) es irreversible. En eso está la gran importancia de Auschwitz. Todo lo que pasó influye en todo lo que aún esté por pasar. No se puede borrarlo del tiempo, no se puede borrarlo del proceso que a falta de otra expresión mejor suelen llamar destino. Y no se puede cambiarlo (Kertész, 2016: 57).

Y si no se puede cambiarlo, ni contarlo con los métodos tradicionales de la literatura, pero al mismo tiempo hace falta la narración para superarlo en la medida posible, la única posibilidad es seguir intentando, seguir buscando una lengua apropiada para textualizar las experiencias difícilmente contables, y dejar, al menos, «esbozos, de capítulos posibles, a lo sumo» (Brizuela, 2012: 81).

\section{Bibliografía}

Brizuela, L. (2012): Una misma noche. Buenos Aires: Alfaguara.

Deffis, E. (2016): «Desafíos de la memoria: Una misma noche de Leopoldo Brizuela y Purgatorio de Tomás Eloy Martínez». Anclajes, 20, 1 (enero-abril 2016), 1-19: http://dx.doi.org/10.19137/anclajes-2016-2011 (20-05-2017).

Eco, U. (1985): Apostillas a «El nombre de la rosa». Barcelona: Lumen. 
Garrido, B. (2012): «Entrevista a Leopoldo Brizuela, Premio Alfaguara de Novela por Una misma noche». Culturamas, 7 de junio: http://www. culturamas.es/blog/2012/06/o7/entrevista-a-leopoldo-brizuela-premioalfaguara-de-novela-por-una-misma-noche/ (20-05-2017).

Heker, L. (1996): El fin de la bistoria. Buenos Aires: Alfaguara.

Heker, L. (2009): «Las formas de la traición en la literatura argentina». En: Sylvia Iparraguirre (ed.), La literatura argentina por escritores argentinos: narradores, poetas y dramaturgos. Buenos Aires: Ediciones Biblioteca Nacional.

Kertész, I. (2014): A végsö kocsma. Budapest: Magvető.

Kertész, I. (2016): La última posada. Trad. de Adan Kovacsics. Barcelona: E1 Acantilado.

Menyhért, A. (2008): Elmondani az elmondbatatlant. Trauma és irodalom. Budapest: Ráció.

Mitchell, J. (1998): «Trauma, Recognition, and the Place of Language». Diacritics. Trauma and Psychoanalysis, 28, 4, 121-133.

Sosa, C. H. (2008): «La memoria sin condicionamientos o sobre cómo relee la dictadura El fin de la Historia de Liliana Heker». Espéculo. Revista de estudios literarios, 39: http://www.ucm.es/info/especulo/numero39/liheker.html (20-05-2017). 
Dóra Bakucz

Pázmány Péter Catholic University

\section{"Sketches, possible chapters, all of all»: Betrayal and rewriting in two Argentine novels with a colophon of a Hungarian writer (Liliana Heker, Leopoldo Brizuela and Imre Kertész)}

Keywords: Argentine literature, trauma, Dirty War, rupture, betrayal

The paper proposes an interdisciplinary and intercultural analysis by comparing two Argentine novels, Liliana Heker's The End of the Story, and Leopoldo Brizuela's The Same Night, by. Starting from a psychoanalytic investigation on how language is affected by traumatic experiences, we study the consequences and possible ways of textualizing the process of assimilating or elaborating experiences connected to the Dirty War in Argentina in both cases. If we consider narration in the third person by an omniscient narrator as the classic form of narration, a particularly unorthodox form would be that of the Hungarian Nobel Prize winner, Imre Kertész, in his last book where he explore the possibility and impossibility of reflecting our reality and sets about writing the story of a novel that he cannot be written as a last protest against those forces that have taken away not only his fate but also that of many others. 
Dóra Bakucz

Katoliška univerza Péter Pázmány

\section{"Kvečjemu osnutki morebitnih poglavij.» Tradicija in ponovno pisanje $\mathbf{v}$ dveh argentinskih romanih $\mathbf{s}$ kolofonom madžarskega pisatelja}

Ključne besede: argentinska književnost, travma, umazana vojna, prelom, izdaja

Članek temelji na interdisciplinarni in medkulturni analizi dveh argentinskih romanov, El fin de la bistoria [Konec zgodbe] Liliane Heker in Una misma noche [Ista noč] Leopolda Brizuele. Avtorica, izhajajoč iz psihoanalitskega pristopa $\mathrm{k}$ vprašanju, kako travmatične izkušnje vplivajo na jezik, prouči posledice in možne oblike za ubesediljenje procesa asimiliranja in predelovanja preživetih dogodkov, ki so v obeh primerih povezani $z$ »umazano vojno« v Argentini. Če kot klasični način pripovedovanja razumemo diskurz vsevednega pripovedovalca v tretji osebi, bi bila druga skrajnost to, kar naredi madžarski nobelovec Imre Kertész v svoji zadnji knjigi, saj v primerjavi z obravnavanima argentinskima avtorjema naredi korak dlje na poti zmožnosi oz. nezmožnosti odsevati resničnost, $\mathrm{s}$ tem ko $\mathrm{v}$ znak protesta proti tistim silam, ki so oropale usode ne le njega, temveč tudi veliko drugih ljudi, napiše zgodbo o romanu, ki ga ne more napisati. 